\title{
Formal venture capital acquisition: can entrepreneurs compensate for the spatial proximity benefits of South East England and 'star' golden-triangle universities?
}

\author{
Cornelius Mueller \\ Durham Business School, Durham University, Mill Hill Lane, Durham DH1 3LB, England; \\ e-mail: cornelius.mueller@gmail.com \\ Paul Westhead 9 \\ Durham Business School, Durham University, Mill Hill Lane, Durham DH1 3LB, England; \\ and Bodø Graduate School of Business, Nordland University, Norway; \\ e-mail: paul.westhead@durham.ac.uk
}

\section{Mike Wright}

Centre for Management Buy-out Research, Imperial College Business School, Exhibition Road, London SW7 2AZ, England; and University of Ghent, Belgium;

e-mail: Mike.Wright@imperial.ac.uk

Received 24 May 2011; in revised form 12 July 2011

\begin{abstract}
Building on the resource-based view of the firm and signalling theory, we challenge the traditional perspective that spatial proximity benefits can be leveraged by university spin-outs (USOs) located in the South East of England (particularly those drawn from 'star' golden-triangle universities with additional reputational benefits), and that USOs located elsewhere will be constrained from obtaining first formal venture capital (VC) required for venture development. With the aid of a longitudinal database of 134 USOs involving unique archival and survey data, event-history analysis identified, counter to the traditional perspective, that USOs located outside the South East of England were significantly more likely to obtain formal VC. Also, counter to the spatial proximity benefits view, star golden-triangle USOs were not significantly more likely to obtain VC. Our evidence supports a spatial mismatch view between investors and investees. Resource-combination signals sent by USOs and favourably received by VC firms were found to differ according to USO location context: USOs located outside the South East of England and star golden-triangle universities that signal the credible presence of habitual founders were more likely to obtain VC. USOs located outside star golden-triangle universities that had previously obtained publicly backed equity finance were also more likely to obtain VC. However, USOs located in the South East of England with reputable management teams were most likely to obtain VC.
\end{abstract}

Keywords: university spin-outs, venture capital, spatial proximity benefits, resources, signalling

\section{Introduction}

Despite inconclusive evidence about the role of universities in local economic development (Rutten and Boekema, 2009), governments are encouraging them to become more entrepreneurial (Lawton Smith and Ho, 2006). Universities can commercialise research knowledge and intellectual property (IP) through developing university spinouts (USOs), to stimulate local economic development through multiplier effects. Those universities which are more successful at commercialising knowledge in the United Kingdom are generally more prestigious and resource rich, and possess better networks with external organisations (Huggins, 2008). 'Star' universities such as Oxford, Cambridge, Imperial College, and University College London report the greatest research income, and largest numbers of USOs, patents, and licences (Lawton Smith, 2007).

A major challenge faced by USOs in exploiting entrepreneurial opportunities is to mobilise resources (Druilhe and Garnsey, 2004). Formal venture capital (VC)

- Corresponding author. 
investment in USOs can stimulate firm growth (Colombo and Grilli, 2005). Entrepreneurs in USOs can leverage pools of internal resources involving relevant experience, knowledge, and social capital to send credible quality signals to outsiders to increase their likelihood of accessing external, formal $\mathrm{VC}$ which provides the funding and expertise needed for USO growth.

Formal VC concerns equity investments and specialised knowledge by formal VC firms (Babcock-Lumish, 2009), whilst hybrid public and private equity fund investments are excluded from this definition. The inability of most USOs to generate substantial growth (Garnsey and Heffernan, 2005) reflects a reluctance and/or inability of entrepreneurs to obtain formal VC, often because they are unwilling to relinquish significant equity shares (Martin et al, 2005). Some USOs obtain government-scheme and/or business-angel finance, but do not subsequently obtain formal $\mathrm{VC}$, which can retard product development and firm growth. USOs face major challenges because formal VC firms are reluctant to invest due to risk and information-asymmetry issues (Huggins, 2008). These last arise because: USO entrepreneurs may have more knowledge than the VC firm; the USO does not have a credible track record; the market is new; or the entrepreneur has been intimately involved in developing the underlying technology. To overcome information-asymmetry problems, USOs (ie, 'signallers') seeking finance from formal VC firms (ie, 'receivers') need to assemble internally costly resource bases which signal the credible quality sought by formal VC firms.

The formal VC market in the United Kingdom is concentrated in the most economically developed South East England region regarding the location of fund managers (Mason and Harrison, 2002). Babcock-Lumish (2009) recently detected a spatial mismatch between investors and investees, with a thriving formal and informal VC funder cluster in London but innovative firms (ie, 'deals') scattered nationwide. A traditional spatial proximity effects view suggests a pronounced distance-decay effect relating to the formal $\mathrm{VC}$ investment behaviour of London-based offices. Need for repeated monitoring visits to investee firms is expected to promote a spatial proximity effect (or geographical bias) favouring investee firms located near to London-based offices. Localities with few USOs, low deal flow, and which are distant from the major national centre of $\mathrm{VC}$ offices may thus have to deal with a low-demand-low-supply equilibrium for formal VC finance (Martin et al, 2005).

These arguments have led to suggestions that the heavily spatially centralised financial VC system may retard the ability of USOs located outside the South East of England to obtain formal VC. However, recent evidence suggests that this perspective is an oversimplification, with not all USOs in the South East of England being able to benefit from the traditional perspective on spatial proximity benefits. A subgroup of premier league, more prestigious, star universities in the region (Huggins, 2008) are likely to possess the network and technology-transfer officer (TTO) experience resources to access external finance. The array of services and infrastructure associated with elite commercialisation systems promoting USOs in Cambridge [Garnsey and Heffernan (2005); for an alternative view see Breznitz (2011)], Oxford (Lawton Smith and Ho, 2006), and Imperial College (Nicolaou and Birley, 2003) are discussed elsewhere. This raises the following questions concerning our understanding of the role of spatial proximity effects, the answers to which have important policy implications. Is access to formal $\mathrm{VC}$ even more concentrated within strong economic regions than generally believed, so that only USOs drawn from star universities in these regions can access VC? Alternatively, do attributes relating to the resources and signals of universities and USOs play a central role in accessing formal VC even outside strong economic regions? If research reputations of universities and star academics can reduce risk perceived by formal VC firms, USOs located outside star universities in the South 
East of England (including London) need to send additional positive signals of quality relating to the resources of their USOs. As a result of information asymmetries between academic entrepreneurs and formal VC firms, entrepreneurs (and supporting TTOs) who do not provide adequate positive founder and firm resource signals may be unable to obtain required formal $\mathrm{VC}$.

The contribution of this study is to explore the applicability of the traditional spatial proximity effects view to explain the take-up of formal VC by USOs in the United Kingdom, which has an economically core region in which formal VC firms are predominantly located. Building upon the resource-based view (RBV) of the firm and signalling theory, we extend prior research on spatial mismatches between investors and investees (Babcock-Lumish, 2009). We propose that USO signallers located outside the South East of England and star golden-triangle universities (ie, Cambridge, Oxford, Imperial College London, Kings College London, and University College London) can compensate for the weaker reputation of their localities and/or universities by sending observable, credible, and costly high-quality resource signals to reduce information asymmetry in order to increase the likelihood of obtaining a first formal VC.

Contrasting with previous USO studies, in which cross-sectional databases were used (Rothaermel et al, 2007), we explore a unique longitudinal dataset involving the population of 579 USOs founded in the United Kingdom between 1990 and 2007, combining archival and survey data from a survey carried out in 2008. Event-history analysis identifies factors related to USOs' ability to obtain a first formal VC. We provide fresh evidence challenging traditional perspectives on spatial proximity benefits, because we detect that USOs located outside the South East of England were more likely to obtain formal VC. Also, counter to the spatial proximity benefits view, star golden-triangle USOs were not significantly more likely to obtain VC. The evidence presented supports a spatial mismatch view between investors and investees. Resource-combination signals sent by USOs and favourably received by VC firms differ according to USO location context. USOs located outside the South East of England and 'star' golden triangle universities that signal the credible presence of habitual founders were more likely to obtain VC. USOs located outside star goldentriangle universities which had previously obtained publicly backed equity finance were also more likely to obtain VC. However, USOs located in the South East of England with reputable management teams were most likely to obtain VC.

\section{Theoretical insights and hypotheses}

\subsection{Signalling theory and RBV of the firm}

Signalling theorists reject the assumption of perfect information held by signallers (ie, USOs) and receivers (ie, VC firms). Information asymmetries between USOs and VC firms may adversely affect the ability of USOs to obtain formal VC. Acquiring information in order to resolve informational asymmetries is costly because signaller attributes may not be readily observable, and the receiver is reliant upon what the signaller is willing to share (Spence, 2002). Signalling theory focuses on the credible communication of positive information to convey positive organisational attributes. Signal quality concerns the underlying, unobservable ability of the signaller to fulfill the demands of an outsider observing the signal (Connelly et al, 2011). The signal highlights the unobservable quality of the signaller to potential receivers via the observable qualities of the signaller. Receivers such as VC firms need to distinguish between high-quality and low-quality signallers. High-quality USOs which signal may receive payoff A, but only payoff B when they do not signal, whilst low-quality USOs receive payoff C when they signal and payoff D when they do not signal (Kirmani and Rao, 2000). 
Signalling is a viable strategy for high-quality USOs when $\mathrm{A}>\mathrm{B}$ and when $\mathrm{D}>\mathrm{C}$. With regard to this separating equilibrium context, receivers (ie, VC firms) are able to distinguish between high-quality and low-quality USOs. Conversely, with reference to a pooling equilibrium context, when high-quality and low-quality USOs benefit from signalling (ie, $\mathrm{A}>\mathrm{B}$ and when $\mathrm{C}>\mathrm{D}$ ), receivers are not able to differentiate between high-quality and low-quality USOs (Connelly et al, 2011).

VC investors may ignore USOs that do not provide adequate information about the quality of the business idea and the management team, potential rewards, and risks. To increase the likelihood of obtaining VC, USOs can provide positive, costly resource signals of credibility, experience, and quality to formal VC firms seeking high-quality proposals to invest in.

We draw upon the RBV of the firm as a conceptual framework which identifies the resources which entrepreneurial firms need to signal to potential formal VC investors. The RBV focuses upon the heterogeneous pool of idiosyncratic resources, which need to be valuable, rare, nonimitable, and nonsubstitutable to ensure competitive advantage (Barney, 1991). They include the following. Firm-specific human resources relate to the management know-how and entrepreneurial experience of the founder and/or founding team. Social capital resources provide important sources for knowledge acquisition and learning from partners and contacts (Yli-Renko et al, 2001), which can be leveraged to mobilise further resources that would be otherwise beyond reach. Intellectual capital and technology embodied in patents may provide unique resources that enable entry into new product or technology markets to generate superior revenues or capital gains.

\subsection{Derivation of hypotheses}

\subsubsection{USO location}

We begin by building on the traditional spatial proximity effects view that suggests that all USOs located in the South East of England (including London) have the potential to leverage the resource provided by being located close to the London financial centre to access finance from formal VC firms, which exhibit a distancedecay effect in their investment behaviour. Our first research question suggests that not all universities located in South East England have developed the networks to leverage potential spatial proximity benefits (Huggins, 2008). USOs drawn from star golden-triangle universities in the South East of England benefiting from the associated reputational, infrastructure, and strong social capital network resources may provide additional credible signals that increase their ability to obtain VC relative to other USOs located in the South East of England and the rest of the United Kingdom. Hence:

Hypothesis 1a: USOs located outside the South East of England will be less likely to obtain first formal VC investment (FFVCI).

Hypothesis 1b: USOs located outside the star golden-triangle universities in the South East of England will be less likely to obtain FFVCI.

\subsubsection{Resource-interaction effects compensating for spatial proximity benefits}

Our second research question suggests that attributes relating to the resources and signals of universities and USOs may play a central role in accessing formal VC, even outside strong economic regions. To address a potential distance-decay effect in formal VC supply, USOs not drawn from the South East of England nor among the star golden-triangle universities may invest in founder and USO resources (Packalen, 2007), leading to compounded, credible, high-quality signals that compensate for locational and university reputational disadvantages. 
2.2.2.1 Academic entrepreneur human capital. USOs involving academic entrepreneurs can possess human capital resources important for venture development. A record of outstanding work in hard science provides a high-quality signal (Shane and Stuart, 2002) that suggests that the entrepreneur knows the true value of the proposed idea, and has the knowledge required to implement it (Zhang, 2009). USOs with founding teams with a range of skills, capabilities, experience, and knowledge-particularly entrepreneurial and management-experience endowment - are generally better equipped to develop and exploit new ideas (Gruber et al, 2012). Management teams with diverse skills provide credible high-quality signals sought by VC providers (Hsu, 2007).

Formal VC firms look for experienced entrepreneurs (Wright et al, 1997) making costly investments in honing their entrepreneurial expertise. These entrepreneurs may have broader and more developed know-how, entrepreneurial capabilities, networks and reputations, and a proven track record of dealing with liabilities of newness (Ozgen and Baron, 2007). Experienced founders may have tested alternative approaches and learnt which are more likely to work. Founders with prior businessownership experience more likely have greater knowledge aiding understanding of their technology, market, and customers, which enables VC investors to reduce operational risks.

USOs located outside the South East of England and the star golden-triangle universities can compensate for potential locational and university reputational benefits by sending observable human capital signals to reduce information asymmetry perceived by potential formal VC investors. Hence:

Hypothesis 2a: USOs located outside the South East of England or the star goldentriangle universities that signal academic professor status will be more likely to obtain FFVCI.

Hypothesis 2b: USOs located outside the South East of England or the star goldentriangle universities that signal the presence of a reputable management team will be more likely to obtain FFVCI.

Hypothesis 2c: USOs located outside the South East of England or the star goldentriangle universities that signal the presence of a habitual entrepreneur key founder who had started a business before will be more likely to obtain FFVCI.

2.2.2.2 Networks and social capital. Deep-bonding social capital provides an important resource that facilitates USO formation and growth (Iyer et al, 2005). University networks can facilitate academic entrepreneurs' networks, and may provide a highquality signal. Continued interaction between a university and a formal VC firm provides a credible quality signal to investors. USOs from universities with a tradition of USO activities can leverage established network links between the university and VC firms (Nicolaou and Birley, 2003). Many universities outside the star golden-triangle universities have invested in bottom-up low-selection and high-support models towards technology-transfer policy. Through investment in incubators, science parks, and TTOs, many universities outside the star golden-triangle universities have proactively sought to change the behaviour of USOs in their localities to become more commercially oriented (Clarysse et al, 2005). By encouraging networking, USOs have broadened their social capital. Hence:

Hypothesis 2d: USOs located outside the South East of England or the star goldentriangle universities that have invested in networking activities and are drawn from universities with a network of previously formally VC-funded USOs will be more likely to obtain FFVCI. 
2.2.2.3 Intellectual capital and technology resources. Costly investment in patenting can signal commitment and credibility to VC firms (Hsu, 2007). Formal VC firms prefer to invest in USOs with patent-protected intellectual resources that create valuable intangible assets (Baum and Silverman, 2004). USOs outside the golden triangle investing in patents can reduce risk and information-asymmetry problems perceived by formal VC firms. Hence:

Hypothesis 2e: USOs located outside the South East of England or the star goldentriangle universities that have invested in patented IP will be more likely to obtain FFVCI.

USOs investing in radical technologies may reap first-mover advantages. Whilst many VC firms want to invest in high-growth-potential firms, some are reluctant to invest in USOs because they are perceived to carry higher risks. Concern may relate to whether the radical innovation involved will be accepted by sufficient customers, plus issues relating to potential market size and competitor response (Lockett et al, 2002). Universities outside the star golden triangle are less likely to employ 'star' scientists, and their technology-transfer policies may generate more USOs which are less engaged in radical innovation. Hence:

Hypothesis 2f: USOs located outside the South East of England or the star golden-triangle universities with main products or services that are not radical will be more likely to obtain FFVCI.

2.2.2.4 Publicly backed equity finance (PBEF). Some USOs located outside the South East of England and the star golden-triangle universities benefit from the activities of local enterprise and development agencies seeking to address barriers to the ability of USOs to obtain PBEF (Wright et al, 2006). Public sector financing can play a role in reducing the information asymmetries perceived by formal VC firms (Huggins, 2008). PBEF investors may become closely involved in developing strategies and control systems in investee firms with incomplete management teams. Further, PBEF investors may require investee firms to develop sound control mechanisms. These resources from PBEF can be used by a USO to signal commitment, expertise and credibility to future external investors. Hence:

Hypothesis 2g: USOs located outside the South East of England or the star goldentriangle universities that have invested in obtaining PBEF and the associated governance structures and credibility associated with PBEF will be more likely to obtain FFVCI.

\section{Data collection and research methodology}

\subsection{Sample, data collection, and respondents}

USOs were identified from the Library House (now Dow Jones) database, which is not widely publicly available. Library House define USOs as start-ups dependent on the formal transfer of IP rights from the university (Lawton Smith and Ho, 2006; Wright et al, 2006), but the university still holds an equity stake. The population of 579 USOs in the United Kingdom founded during the period 1990 to 2007, the most active period in USO formation, was identified.

Library House, Companies House, FAME, and the Annual Business Inquiry (ABI) databases were explored to identify information relating to each USO's status, market size, industry context, and prior take-up of external financing. The esp@cenet database was used to identify the annual number of patents filed by each USO. No information was publicly available on human capital profiles of USO founders and USOs networks. An online survey designed to collect this information was sent in February-March 2008 to key founders in each USO; e-mail addresses were obtained from Library House 
and an Internet search. Returns were obtained from 134 respondents, with a response rate of $23 \%$ - higher than similar studies (Becheikh et al, 2006). A firm is defined as surviving if still in business by the start of 2008. In total, 125 USOs had survived and 9 had closed. The $93.3 \%$ survival rate is consistent with USO studies in the United States (94.4\%) (Zhang, 2009). No USOs had been acquired.

A panel database was created with annual observations for the period of USO formations and formal VC funding events between 1990 and 2007. Event-history analysis was used to identify factors significantly related to USOs' ability to obtain first formal VC.

\subsection{Sample representation}

Mann Whitney ' $U$ '-tests confirmed no statistically significant response bias between respondents and nonrespondents regarding firm age, total disclosed funding, funding events, year of most recent external investment, total average of years until first external investment, and number of previous USOs from the university of origin. Chi-square tests confirmed no statistically significant response bias between respondents and nonrespondents regarding region of origin, industry, university of origin, whether the university was a member of the leading Russell Group, and whether the USO was from a star golden-triangle university. The Russell Group comprises twenty leading research-led universities that receive two thirds of research grants and contract funding in the United Kingdom. We believe our sample is representative of the USO population in the United Kingdom.

\subsection{Measures}

\subsubsection{Dependent variable}

Key founders were asked for the percentage distribution of equity ownership in their USOs regarding the following categories: your share (1), management (2), university (3), other companies (4), venture capitalists (5), business angels (6), public funds (7), hybrid public and private equity funds (8), IPO (public shares) (9), and other (10). For USOs obtaining finance from formal venture capitalists (category 5), the timing of VC investment between 1 January 1990 and 31 December 2007 was cross-checked with Library House information. Key founders reporting that $1 \%$ or more of their USO's equity was owned by formal VC firms (category 5 above) were allocated a value of ' 1 ', and ' 0 ' otherwise (First VC Funding).

\subsubsection{Independent variables}

Databases were used to identify each USO's main operational premises. USOs located in the South East of England (including London) standard region were allocated a value of ' 1 ', and ' 0 ' otherwise (SEL). USOs located in star golden-triangle universities were allocated a value of ' 1 ', and '0' otherwise (GTL). Following Yip and Tsang (2007), variables relating to 'non-South-East-of-England' and 'non-golden-triangle' location were computed. USOs not located in the South East of England were allocated a value of ' 1 ', and ' 0 ' otherwise (NSEL). Further, USOs not located in the golden triangle were allocated a value of ' 1 ', and ' 0 ' otherwise (NGTL).

Interaction effects (Yip and Tsang, 2007) were explored with regard to SEL and NSEL as well as GTL and NGTL. The following interaction variables relating to USO location outside the South East of England were computed by multiplying USO NSEL with each USO internal resource-profile signal: NSEL $\times$ Professor, NSEL $\times$ Team, NSEL $\times$ Habitual, NSEL $\times$ Ties, NSEL $\times$ Patent, NSEL $\times$ Radicalness, and NSEL $\times$ PBEF. Each interaction variable was computed with regard to USO SEL. Interaction variables for NGTL and GTL were also computed. 


\subsubsection{Control variables}

Firm age (in years) is the time between the founding year and the year of obtaining first formal VC for the 72 USOs with a first formal VC. Some 62 USOs failed to obtain formal $\mathrm{VC}$, and their age was monitored from their founding year to 31 December 2007.

Industry environments differ regarding entry costs, average performance, reinvestment intensity, and sunk costs, which may influence an entrepreneur's ability to provide quality signals about potential market size to $\mathrm{VC}$ investors. Databases were used to identify each USO's primary industrial activity. USOs primarily engaged in pharmaceuticals or biotechnology are likely to differ from USOs in other sectors due to their higher investment needs and longer time-to-market. USOs engaged in pharmaceuticals or biotechnology were allocated a value of ' 1 ', and ' 0 ' otherwise (Pharmabio).

Market size in terms of employee numbers in each USO's primary four-digit industry code was collected from the Office for National Statistics. For USOs obtaining formal $\mathrm{VC}$, market-size information was annually monitored from the founding year to the year in which they obtained their first formal VC. The market size of USOs that did not obtain formal VC was monitored between the founding year and 31 December 2007. Data on annual number of employees in each industry was log transformed (Log Market Size).

Cyclical effects can shape VC supply. The annual amount of VC for early-stage investments in the United Kingdom was monitored during the period 2000-07; these figures were log transformed (Annual VC Supply). The annual rate of return (percent) from early-stage VC investments in the United Kingdom was also collected from British Venture Capital Association (BVCA) publications covering the period 2000-07 (Annual VC Return).

USOs obtaining formal VC during the period 1990-2000, associated with the new economy, may have benefited from an increasingly 'hot' period in the technology and investment cycle, and greater VC investment interest. During the long period of economic growth throughout the 1990s, governments sought to encourage the creation of new technology based firms (Bank of England, 2001). This hot period culminated in the peak of the so-called 'dot.com boom' in 2000, following which formal VC investments fell [see BVCA annual Investment Activity Reports (eg, BVCA, 2010)]. Financiers have sought to hedge their risk due to overvalued investments (Lockett et al, 2002). Structural breaks and macroeconomic shocks can shape whether USOs obtained a first formal VC. USOs obtaining formal VC prior to 1st January 2000 were allocated a value of ' 1 ', and ' 0 ' otherwise (VC Pre-2000). USOs that had survived as independent firms by 2008 were allocated a value ' 1 ', and ' 0 ' otherwise (Survival).

Each key founder indicated whether they had been a full university professor when the USO had been established. Founders reporting that they had been professors were allocated a value of ' 1 ', and ' 0 ' otherwise (Professor).

Statements relating to reputation, to deal with risk and information-asymmetry problems, were identified (Podolny, 1993). Key founders were presented with the following statements about the founding team: 'at least one member of the team had founded a successful company before'; 'we expected our team would be credible to potential investors'; 'a trusted third party believed our team could successfully start a company'; and 'we thought that our team's experience would be attractive to potential investors'. The following five-point Likert scale was used: 'strongly disagree' (1), 'disagree' (2), 'neither agree nor disagree' (3), 'agree' (4), and 'strongly agree' (5). A principal components analysis (PCA) identified a conceptually meaningful component. The Bartlett test of sphericity was significant at the 0.001 level $\left(\chi^{2}=544.02\right)$. 
The Kaiser-Meyer-Olkin (KMO) measure of 0.81 concerning sampling adequacy was sufficient. The scale had a Cronbach's $\alpha$ of 0.91 . Component scores relating to this valid and reliable scale were computed (Team).

Key founders indicated whether they had started at least one firm before the surveyed USO (Shane and Stuart, 2002): founders indicating they had started a firm before were allocated a value of ' 1 ', and ' 0 ' otherwise (Habitual).

The Library House database was used to assess indirect ties (Podolny, 1993) by calculating the percentage of previous USOs which had already obtained formal VC located at the same university. The percentage of indirect ties was monitored annually between the founding year and the year of obtaining the first formal VC for USOs which did obtain VC. The percentage of indirect ties was monitored annually between the founding years and 31 December 2007 for USOs which did not obtain a first formal VC. The percentage rate of indirect ties was normalised using the following ten categories: ' 0 to $10 \%$ ' (1), ' 11 to $20 \%$ ' (2), ' 21 to $30 \%$ ' (3), ' 31 to $40 \%$ ' (4), ' 41 to $50 \%$ ' (5), '51 to $60 \%$ ' (6), '61 to $70 \%$ ' (7), ' 71 to $80 \%$ ' (8), ' 81 to $90 \%$ ' (9), and '91 to $100 \%$ ' (10) (Ties).

Key founders indicated whether they had filed at least one patent in the name of the USO prior to attracting the first formal VC (Hsu, 2007). From the year in which USOs had filed for at least one patent, they were allocated a value of ' 1 ' for all their annual observations. Annual observations of USOs not filing any patents were allocated a value of ' 0 ' (Patent). Responses were cross-checked with information held on the esp@cenet European Patent Office database.

Marvel and Lumpkin (2007) developed an innovation radicalness construct with regard to the following statements: 'large group of customers already use a very similar product/service'; 'product/service represents an entirely new type of product/service'; 'the product/service may be described as a new technology'; 'product/service is a gradual progression upon the last generation'; 'product/service is a product-line extension'; 'product/service satisfies a need not met by competitors'; and 'product/service is a new twist on an old theme'. The following four-point Likert scale was used: 'strongly disagree' (1), 'disagree' (2), 'agree' (3), and 'strongly agree' (4). For each USO, responses were allocated to each statement based on the objective and consistent secondary company report information held on the Library House database. A PCA identified a conceptually meaningful component relating to the following market risk from radical innovation statements: 'large group of customers already use a very similar product/service'; 'product/service represents an entirely new type of product/service'; 'product/service satisfies a need not met by competitors'; and 'product/service is a new twist on an old theme'. The Bartlett test of sphericity was significant at the 0.001 level $\left(\chi^{2}=80.76\right)$. The KMO measure of 0.67 was sufficient. The scale had a Cronbach's $\alpha$ of 0.65. Component scores relating to this valid and reliable scale were computed (Radicalness).

Take-up of PBEF was annually monitored between the founding year and the year of first formal VC for USOs which obtained formal VC; it was annually monitored between the founding year and 31 December 2007 for other USOs. Responses were cross-checked with the Library House database. Key founders indicating that they had obtained PBEF were allocated a value of ' 1 ', and ' 0 ' otherwise (PBEF).

\subsection{Validity and common-method bias}

The online questionnaire was tested during a pilot survey. Practitioner conferences relating to USOs and start-up financing were attended to ensure understanding of USO financing needs. An early version was revised in line with comments from two 
academic entrepreneurs. To check face validity, ten academic entrepreneurs were contacted and comments from this pilot were incorporated in a revised questionnaire.

Common-method bias was minimised through protection of respondent anonymity; reducing statement ambiguity by pretesting; a short structured questionnaire that would encourage accurate responses; and statements relating to the dependent variable were not located close to control variables. Variables were also collected from various archival data sources: Library House, Companies House, FAME, ABI, and esp@cenet. Responses from one data source were validated with responses from an alternative source.

\subsection{Survivor bias}

No significant differences between the 517 USO survivors and the 62 closed USOs up to the 31 December 2007 were detected with regard to the following widely used firm survival measures: USO region, sector, university Russell Group membership, and survival of surveyed respondents ( $\chi^{2}$ tests); firm age, number of funding events, and amount of formal VC (Mann-Whitney ' $U$ ' tests). In all reported models, firm survival was consistently not found to be significant. With regard to these indicators, there is no evidence to suggest that the results are distorted by firm-survivor bias.

\subsection{Data analysis}

Event-history analysis models are reported to test our presented hypotheses (Blossfeld et al, 2007). All models were significant at the 0.001 level. Base models (ie, control and location variables) and full models (ie, control, location, and interaction variables) are presented relating to USO location in the South East of England (SEL). Sensitivity analysis models were then computed for USO location outside the South East of England (NSEL). Models were also computed for NGTL and GTL.

\section{Results}

Some 72 USOs $(54 \%)$ had obtained a first formal VC. Model 1 relates to the control variables and SEL (table 1). Older USOs and USOs engaged in pharmaceuticals or biotechnology (Pharmabio) were significantly less likely to obtain formal VC. High annual amounts of VC for early-stage investments (Annual VC Supply), and the supply of finance during the hot periods in the technology and investment cycle (VC Pre-2000) significantly increased the likelihood of obtaining VC. USOs with strong indirect ties to VC firms (Ties), USOs filing at least one patent (Patent), and with professors as founders (Professor) were significantly more likely to obtain VC. SEL USOs were significantly less likely to obtain formal VC. Hypothesis H1a is thus not supported.

SEL, SEL interaction variables, and control variables were explored in model 2. Positive significant SEL $\times$ Team and negative significant $S E L \times$ Habitual interactions were detected. USOs with reputable management teams in the South East of England were more likely to obtain VC. NSEL, NSEL interaction variables, and control variables were explored in model 3. Negative significant NSEL $\times$ Team and positive significant NSEL $\times$ Habitual interactions were detected. USOs located outside the South East of England and with habitual founders were significantly more likely to obtain formal VC.

Since the dependent and independent variables are binary in a logarithmic form, the marginal effects reported in table 1 are the odds (Cameron and Trivedi, 2005) of obtaining VC, for example, given the presence of habitual founders. The NSEL $\times$ Habitual interaction increased the odds of obtaining VC by 2.8 (model 3), whilst the SEL $\times$ Team interaction increased the odds of obtaining VC by 1.0 (model 2). Here, hypothesis H2c is supported. 
Table 1. Ability of university spin-out (USO) to obtain first formal venture capital (VC) investment-South East of England (SEL) location: event-history analysis models.

\begin{tabular}{|c|c|c|c|c|c|c|}
\hline \multirow[t]{2}{*}{ Independent variable } & \multicolumn{2}{|c|}{ Model 1} & \multicolumn{2}{|c|}{ Model 2} & \multicolumn{2}{|c|}{ Model 3} \\
\hline & $\mathrm{d} y / \mathrm{d} x$ & SE & $\mathrm{d} y / \mathrm{d} x$ & SE & $\mathrm{d} y / \mathrm{d} x$ & SE \\
\hline
\end{tabular}

Location

SEL

$-1.01 * \quad 0.43$

1.93

1.16

NSEL

Interaction SEL

SEL $\times$ Professor

SEL $\times$ Team

SEL $\times$ Habitual

SEL $\times$ Ties

SEL $\times$ Patent

SEL $\times$ Radicalness

SEL $\times$ PBEF

Interaction NSEL

NSEL $\times$ Professor

NSEL $\times$ Team

NSEL $\times$ Habitual

NSEL $\times$ Ties

NSEL $\times$ Patent

NSEL $\times$ Radicalness

NSEL $\times$ PBEF

$\begin{array}{ll}-0.05 & 0.61 \\ 1.02^{*} & 0.45 \\ -3.79 * * * & 1.24 \\ -0.09 & 0.17 \\ -0.95 & 0.78 \\ 0.31 & 0.35 \\ -0.85 & 0.71\end{array}$

Control variables

$\begin{array}{lcc}\text { Firm age } & -2.16^{* * *} & 0.20 \\ \text { Pharmabio } & -0.86^{*} & 0.40 \\ \text { Log Market Size } & 0.31 & 0.19 \\ \text { Annual VC Supply } & 0.50^{* * *} & 0.15 \\ \text { Annual VC Return } & -1.03 & 1.49 \\ \text { VC Pre-2000 } & 3.28^{* * *} & 0.56 \\ \text { Firm Survival } & -1.26 & 1.09 \\ \text { Professor } & 0.80^{*} & 0.34 \\ \text { Team } & 0.39 & 0.21 \\ \text { Habitual } & -0.01 & 0.38 \\ \text { Ties } & 0.37^{* * *} & 0.10 \\ \text { Patent } & 1.58^{* * *} & 0.46 \\ \text { Radicalness } & 0.10 & 0.16 \\ \text { PBEF } & 0.32 & 0.33 \\ \text { Wald } \chi^{2} & 238.98^{* * *} & \\ \text { Log-likelihood } & -48.67 & \end{array}$

$\begin{array}{cc}-2.20 * * * & 0.21 \\ -0.79^{*} & 0.38 \\ 0.36 & 0.20 \\ 0.49^{* * *} & 0.15 \\ -1.12 & 1.50 \\ 3.44^{* * *} & 0.56 \\ -0.82 & 0.97 \\ 0.76 & 0.43 \\ -0.05 & 0.22 \\ 1.44^{* *} & 0.54 \\ 0.36^{* * *} & 0.12 \\ 1.93^{* * *} & 0.55 \\ 0.01 & 0.21 \\ 0.90^{*} & 0.42 \\ 260.22^{* * *} & \\ -38.04 & \end{array}$

1.16

$* p<0.05 ; * *<p<0.01 ; * * * p<0.001$ (two-tailed tests).

Notes: 134 USOs with 696 annual observations between 1 January 1990 and 31 December 2007; $\mathrm{d} y / \mathrm{d} x=$ marginal effects; $\mathrm{SE}=$ standard errors.

Model 4 relates to the control variables and GTL (table 2). Older USOs were significantly less likely to obtain formal VC. High annual amounts of VC for early stage investments (Annual VC Supply), and the supply of finance during the hot periods in the technology and investment cycle (VC Pre-2000) significantly increased the likelihood of obtaining VC. USOs with strong indirect ties to VC firms (Ties), USOs filing at least one patent (Patent), with professors as founders (Professor), and reputable management teams (Teams) were significantly more likely to obtain VC. Although not statistically significant, GTL USOs were less likely to obtain VC. Hypothesis H1b is thus not supported. 
Table 2. Ability of university spin-out (USO) to obtain first formal venture capital (VC) investment - 'star' golden-triangle location (GTL): event-history analysis.

\begin{tabular}{|c|c|c|c|c|c|c|}
\hline \multirow[t]{2}{*}{ Independent variable } & \multicolumn{2}{|c|}{ Model 4} & \multicolumn{2}{|c|}{ Model 5} & \multicolumn{2}{|c|}{ Model 6} \\
\hline & $\mathrm{d} y / \mathrm{d} x$ & SE & $\mathrm{d} y / \mathrm{d} x$ & SE & $\mathrm{d} y / \mathrm{d} x$ & SE \\
\hline
\end{tabular}

Location

GTL

$-0.66 \quad 0.39$

1.12

1.44

NGTL

Interaction GTL

GTL $\times$ Professor

GTL $\times$ Team

GTL $\times$ Habitual

GTL $\times$ Ties

GTL $\times$ Patent

GTL $\times$ Radicalness

GTL $\times$ PBEF

$\begin{array}{cc}0.48 & 0.65 \\ 0.69 & 0.44 \\ -3.39^{* *} & 1.21 \\ 0.05 & 0.21 \\ -0.57 & 0.77 \\ 0.08 & 0.40 \\ -1.46^{*} & 0.85\end{array}$

Interaction NGTL

NGTL $\times$ Professor

NGTL $\times$ Team

NGTL $\times$ Habitual

NGTL $\times$ Ties

NGTL $\times$ Patent

NGTL $\times$ Radicalness

NGTL $\times$ PBEF

$\begin{array}{cc}-0.50 & 0.72 \\ -0.69 & 0.44 \\ 2.58^{* * *} & 0.73 \\ -0.05 & 0.21 \\ 0.54 & 0.69 \\ -0.08 & 0.40 \\ 1.25^{*} & 0.63\end{array}$

Control variables

$\begin{array}{lcl}\text { Firm age } & -2.16^{* * *} & 0.21 \\ \text { Pharmabio } & -0.76 & 0.41 \\ \text { Log Market Size } & 0.32 & 0.20 \\ \text { Annual VC Supply } & 0.50^{* * *} & 0.15 \\ \text { Annual VC Return } & -0.82 & 1.51 \\ \text { VC Pre-2000 } & 3.24^{* * *} & 0.56 \\ \text { Firm Survival } & -1.27 & 1.11 \\ \text { Professor } & 0.77^{*} & 0.35 \\ \text { Team } & 0.46^{*} & 0.21 \\ \text { Habitual } & -0.23 & 0.37 \\ \text { Ties } & 0.33^{* * *} & 0.10 \\ \text { Patent } & 1.40^{* * *} & 0.44 \\ \text { Radicalness } & 0.17 & 0.16 \\ \text { PBEF } & 0.37 & 0.33 \\ \text { Wald } \chi^{2} & 235.45^{* * *} & \\ \text { Log-likelihood } & -50.43 & \end{array}$

$\begin{array}{ll}-2.06^{* * * *} & 0.19 \\ -0.55 & 0.38 \\ 0.31 & 0.20 \\ 0.39^{* * *} & 0.13 \\ -1.06 & 1.44 \\ 3.10^{* * *} & 0.51 \\ -1.04 & 0.99 \\ 0.56 & 0.38 \\ 0.28 & 0.21 \\ 0.69 & 0.43 \\ 0.24^{* *} & 0.08 \\ 1.46^{* * *} & 0.46 \\ 0.34 & 0.20 \\ 0.98^{*} & 0.41 \\ 252.00^{* * *} & \\ -42.16 & \end{array}$

1.44

$* p<0.05 ; * * p<0.01 ; * * * p<0.001$ (two-tailed tests).

Notes: 134 USOs with 696 annual observations between 1 January 1990 and 31 December 2007; $\mathrm{d} y / \mathrm{d} x=$ marginal effects; $\mathrm{SE}=$ standard errors.

GTL, GTL interaction variables, and control variables were explored in model 5. Negative significant GTL $\times$ Habitual and GTL $\times$ PBEF interactions were detected. NGTL, NGTL interaction variables, and control variables were explored in model 6. Positive significant GTL $\times$ Habitual and GTL $\times$ PBEF interactions were detected. USOs located outside the star golden-triangle universities with habitual founders were significantly more likely to obtain formal VC. Also, USOs with prior publicly backed equity finance were more likely to obtain VC. The NGTL $\times$ Habitual interaction increased the odds of obtaining VC by 2.6, whilst the NGTL $\times$ PBEF interaction increased the odds of obtaining VC by 1.3 (model 6). Hypotheses $\mathrm{H} 2 \mathrm{c}$ and $\mathrm{H} 2 \mathrm{~g}$ are supported. 
To explore whether broader university reputational effects were linked to USO likelihood of obtaining formal $\mathrm{VC}$, models were computed relating to whether USOs were located in leading research-led Russell Group universities or not. None of the location or interaction variables was significant. The assumed reputational benefits of Russell Group universities do not appear to be a key credible signal that is sought by formal VC firms.

\section{Conclusions}

Uncovering linkages between a USO's resource profile (ie, signals) and its ability to obtain formal $\mathrm{VC}$ is of considerable theoretical and practical relevance. Our analysis challenges the traditional perspective that spatial proximity benefits can be leveraged by USOs located in the South East of England (particularly those drawn from star golden-triangle universities with additional reputational benefits), and that USOs located elsewhere will be constrained from obtaining their first formal VC. In answer to our first research question, we do not find evidence to suggest that access to formal $\mathrm{VC}$ is even more concentrated within strong economic regions than is generally believed so that only USOs drawn from star universities in these regions can access VC. However, we do find support for our second research question that suggests that USOs not located in the South East of England or located in star golden-triangle universities have to send additional positive signals of quality relating to the resources of their USOs. Notably, we detect that the resources and signals of entrepreneurs and USOs play a central role in accessing formal VC outside strong economic regions. Consistent with a spatial mismatch view between investors and investees (BabcockLumish, 2009), rather than a spatial proximity effects view, SEL USOs were significantly less likely to obtain formal VC. The selective approach adopted by some star goldentriangle universities appears to be reducing the likelihood that more USOs drawn from these contexts will obtain formal VC, which may potentially impair firm and local economic development (Breznitz, 2011).

Our examination of whether USOs located outside the South East of England (or not drawn from star golden-triangle universities) compensate for the absence of spatial proximity benefits by combining NSEL (or NGTL) with founder and USO resources to signal credible quality to VC firms shows that SEL and NGTL USOs that exhibited resource-substitution behaviour increased their likelihood of obtaining formal VC. We thus extend prior research by showing that the resource-combination signals sent by USOs and favourably received by VC firms were found to differ according to the USO location context. USOs located outside the South East of England and star golden-triangle universities that signal the credible presence of habitual founders were more likely to obtain VC. USOs located outside star golden-triangle universities that had previously obtained PBEF were also more likely to obtain VC. However, USOs located in the South East of England with reputable management teams were more likely to obtain VC. Experience is, therefore, a credible signal sought by formal VC firms (Politis, 2008).

We extend previous studies by focusing specifically on how differential access to formal VC may contribute to explaining shortcomings in the policy contribution of USOs to innovation-led local economic development. Also, we extend prior research by demonstrating that the USO founder and firm-resource signals provided by NSEL and NGTL USOs, notably key founder prior business ownership experience, can compensate for potential spatial proximity benefits that could be leveraged by USOs located in a strong economic region, or the reputational benefits of star golden-triangle universities located in a strong economic region. Our findings question the view that USOs from the South East of England and star golden-triangle universities have an 
inbuilt advantage in obtaining formal VC. Rather, attributes relating to the resources of founders and USOs appear to play a central role in accessing formal VC. Some formal VC firms are seeking to develop closer relationships with star golden-triangle universities, but this does not appear to have increased the likelihood of GTL USOs obtaining VC. VC firms appear to prefer founder experience rather than just university reputation with regard to their $\mathrm{VC}$-allocation decisions. Additional research is warranted to explore whether this trend changes over time.

Our findings have implications for policy addressing the locational disadvantages of NSEL and NGTL USOs. We suggest that the onus is on entrepreneurs to provide the credible signals sought by formal VC investors. Practitioners in local enterprise agencies, incubators, science parks, and TTOs may also have a role in encouraging NGTL USOs to consider strategies that combine resources to facilitate more USOs to provide the positive credible signals sought by formal VC investors seeking to reduce their risk exposure whilst also seeking deals with high up-side gains. They have a role in facilitating local networks that encourage USO founders to internally assemble and manage costly resource bases that signal USO observable credible quality to formal $\mathrm{VC}$ firms.

Policy measures may promote the provision of PBEF to stimulate more USOs to subsequently obtain formal VC. We detected that NGTL USOs with prior PBEF were significantly more likely to obtain VC. Our evidence, therefore, does not consistently suggest that the take-up of PBEF was a credible quality signal sought and favourably received by formal VC firms. Additional research is warranted to guide practitioner resource-allocation decisions relating to this topical debate.

This study has limitations that provide future research opportunities. Our results can be generalised to the United Kingdom and, potentially, to other contexts where VC firm offices are concentrated in a core region. Additional research in a variety of national contexts is warranted to explore the external validity of our findings. Doubt may be cast on the wider validity of self-report measures, although key-informant founders can provide reliable information about firm characteristics and the issues faced (Gruber et al, 2012). To reduce the problem of common-methods bias and to improve construct validity, studies need to complement information from key informants with information from secondary sources. Future studies may consider finer measures of the extent and nature of prior entrepreneurial experience (Ucbasaran et al, 2010). Additional research is warranted to explore whether firms that obtain formal VC subsequently report superior levels of performance, whilst controlling for potential selection-bias issues relating to USO ability to obtain formal VC. The USO definition selected can impact on the size and composition of the identified and monitored USO population. Our online survey was conducted in 2008 - at the time of the peak of the formal VC market. After the fall that occurred from the late 2008 through 2009, the VC market improved in 2010 - not just in the South East of England (including London) but also in many regions (BVCA, 2010). To some extent this may suggest that the market has experienced a general cyclical effect. However, given the severity of the financial crisis, VC firms may have become more risk averse in their decisions to invest, reinforcing a need to focus on those entrepreneurs who are able to signal their greater human capital resource derived from prior entrepreneurial experience. Additional studies are warranted to explore whether the results presented here are sensitive to the USO definition operationalised, and the time frame of analysis.

Acknowledgements. The authors gratefully acknowledge the insightful comments of the referees but the views in this paper are the authors alone. 


\section{References}

Babcock-Lumish T L, 2009 Financing Clusters of Innovation: The Geography of Venture Capital Investment, $U S$ and $U K$ available at SSRN, http://ssrn.com/abstract $=1358931$

Bank of England, 2001 The Financing of Technology-based Small Firms, 2nd Report Bank of England, London

Barney J, 1991, "Firm resources and sustained competitive advantage" Journal of Management 17 $99-120$

Baum J A C, Silverman B S, 2004, "Picking winners or building them? Alliance, intellectual, and human capital as selection criteria in venture financing and performance of biotechnology startups" Journal of Business Venturing 19411 - 436

Becheikh N, Landry R, Amara N, 2006, "Lessons from innovation empirical studies in the manufacturing sector: a systematic review of the literature from 1993-2003" Technovation $26644-664$

Blossfeld H-P, Golsch K, Rohwer G, 2007 Event History Analysis With Stata (Routledge, London)

Breznitz S M, 2011, "Improving or impairing? Following technology transfer changes at the University of Cambridge" Regional Studies $\mathbf{4 5} 463$ - 478

BVCA, 2000 - 2007 BVCA Private Equity and Venture Capital: Performance Measurement Survey 2000 - 2007 British Venture Capital Association, PricewaterhouseCoopers, London

BVCA, 2010 BVCA Investment Activity Report British Venture Capital Association, London

Cameron A C, Trivedi P K, 2005 Supplement to Microeconometrics: Methods and Applications (Cambridge University Press, New York)

Clarysse B, Wright M, Lockett A, van de Elde E, Vohora A, 2005, "Spinning out new ventures: a typology of incubation strategies from European research institutions" Journal of Business Venturing $20183-216$

Colombo M, Grilli L, 2005, "Founders' human capital and the growth of new technology-based firms: a competence-based view" Research Policy 34 795-816

Connelly B L, Certo S T, Ireland R D, Reutzel C R, 2011, "Signaling theory: a review and assessment" Journal of Management $3739-67$

Druilhe C, Garnsey E, 2004, "Do academic spin-outs differ and does it matter?" Journal of Technology Transfer $29269-285$

Garnsey E, Heffernan P, 2005, "High-technology clustering through spin-out and attraction: the Cambridge case" Regional Studies $391127-1144$

Gruber M, MacMillan I C, Thompson J D, 2012, "From minds to markets: how human capital endowments shape market opportunity identification of technology start-ups" Journal of Management forthcoming

Hsu D H, 2007, "Experienced entrepreneurial founders, organizational capital, and venture capital funding" Research Policy 36722 - 741

Huggins R, 2008, "Universities and knowledge-based venturing: finance, management and networks in London" Entrepreneurship and Regional Development $20185-206$

Iyer S, Kitson M, Toh B, 2005, "Social capital, economic growth and regional development" Regional Studies 391015 - 1040

Kirmani A, Rao A R, 2000, "No pain, no gain. A critical review of the literature on signalling unobservable product quality" Journal of Marketing 64 66-79

Lawton Smith H, 2007, "Universities, innovation, and territorial development: a review of the evidence" Environment and Planning C: Government and Policy 2598 - 114

Lawton Smith H, Ho K, 2006, "Measuring the performance of Oxford University, Oxford Brookes University and the government laboratories' spin-off companies" Research Policy 351554 - 1568

Lockett A, Murray G, Wright M, 2002, "Do UK venture capitalists still have a bias against investment in new technology firms?" Research Policy 31 1009-1030

Martin R, Berndt C, Klagge B, Sunley P, 2005, "Spatial proximity effects and regional equity gaps in the venture capital market: evidence from Germany and the United Kingdom" Environment and Planning A $371207-1231$

Marvel M R, Lumpkin G T, 2007, “Technology entrepreneurs' human capital and its effects on innovation radicalness" Entrepreneurship Theory and Practice 31807 - 828

Mason C M, Harrison R T, 2002, "The geography of venture capital investments in the UK" Transactions of the Institute of British Geographers, New Series 27 427-451

Nicolaou N, Birley S, 2003, "Social networks in organizational emergence: the university spinout phenomenon” Management Science 491702 - 1725

Ozgen E, Baron R, 2007, "Social sources of information in opportunity recognition: effects of mentors, industry networks, and professional forums" Journal of Business Venturing 22 174-192 
Packalen K A, 2007, "Complementing capital: the role of status, demographic features, and social capital in founding teams' abilities to obtain resources" Entrepreneurship Theory and Practice $31873-891$

Podolny J M, 1993, "A status-based model of market competition" American Journal of Sociology $98829-872$

Politis D, 2008, "Business angels and value added: what do we know and where do we go?" Venture Capital 10127 - 147

Rothaermel F T, Agung S D, Jiang L, 2007, "University entrepreneurship: a taxonomy of the literature" Industrial and Corporate Change 16691 - 791

Rutten R, Boekema F, 2009, "Universities and regional development" Regional Studies 43771 - 775

Shane S, Stuart T, 2002, "Organizational endowments and the performance of university start-ups" Management Science 48154 - 170

Spence M, 2002, "Signaling in retrospect and the informational structure of markets" American Economic Review $92434-459$

Ucbasaran D, Westhead P, Wright M, Flores M, 2010, "The nature of entrepreneurial experience, business failure and comparative optimism" Journal of Business Venturing 25541 - 555

Wright M, Robbie K, Ennew C, 1997, "Venture capitalists and serial entrepreneurs" Journal of Business Venturing 12227 - 249

Wright M, Clarysse B, Lockett A, Binks M, 2006, "University spin-out companies and venture capital" Research Policy 35481 - 501

Yip P S L, Tsang E W K, 2007, "Interpreting dummy variables and their interaction effects in strategy research" Strategic Organization $513-30$

Yli-Renko H, Autio E, Sapienza H, 2001, "Social capital, knowledge acquisition, and knowledge exploitation in young, technology-based firms" Strategic Management Journal 22 587-613

Zhang J, 2009, "The performance of university spin-offs: an exploratory analysis using venture capital data" Journal of Technology Transfer 34255 - 285 
Conditions of use. This article may be downloaded from the E\&P website for personal research by members of subscribing organisations. This PDF may not be placed on any website (or other online distribution system) without permission of the publisher. 